\title{
Regulação dos setores em rede para além dos valores econômicos: uma análise das políticas de interconexão IP para suporte a serviços de voz na União Europeia a partir das Teorias do Interesse Público
}

Regulating Network Industries beyond Economic Theories: An Analysis of IP

Interconnection Policies to Support Voice Services in the EU from the perspective of Public Interest Theories

\section{Victor Oliveira Fernandes*}

\section{Resumo}

Propósito - $\mathrm{O}$ artigo analisa de que forma teorias de regulação econômica dos setores em rede podem antecipar o comportamento das autoridades reguladoras no setor de telecomunicações contemporâneo, especificamente no que concerne à adoção de políticas de acesso e interconexão de redes.

Metodologia/abordagem/design - Inicialmente, o trabalho examina os principais argumentos econômicos de regulação de setores em rede sustentados pela literatura especializada, destacando estudos recentes que consideram que o dinamismo tecnológico inerente ao setor de telecomunicações tornaria desnecessária uma intervenção estatal mais efetiva na imposição de obrigações de interconexão de redes. Em seguida, são exploradas algumas das críticas feitas pelas Teorias do Interesse Público às abordagens regulatórias baseadas exclusivamente na perseguição de valores econômicos, destacando-se de que forma tais críticas podem ser endereçadas às teorias examinadas na primeira parte do trabalho. Por fim, será examinado o quadro normativo comum europeu aplicável às políticas de acesso e interconexões de redes, bem como decisões recentes de Agências Reguladoras Nacionais de dois países da União Europeia (França e Alemanha), investigando-se como as abordagens econômicas de regulação dos setores em rede podem antecipar o comportamento dessas entidades reguladoras.

Resultados - A partir das decisões examinadas, é possível inferir que, nessas jurisdições, a imposição de obrigações de interconexão IP fundamenta-se em princípios como o da concorrência efetiva e o da neutralidade tecnológica, que não se reduzem ao ideal econômico neoclássico de eficiência alocativa. Assim, nesse contexto, pode-se dizer que a intervenção regulatória perseguiu objetivos substantivos de regulação para além dos valores econômicos invocados pelas tradicionais teorias de regulação dos setores em rede.

Palavras-chave: regulação - interconexão IP - Teorias do Interesse Público da Regulação

\footnotetext{
*Mestrando em Direito, Estado e Constituição pela Universidade de Brasília (UnB) e graduado em Direito pela mesma instituição de ensino. Professor de Direito Constitucional do curso de graduação em Direito do Instituto Brasiliense de Direito Público (IDP). É Especialista em Regulação de Serviços Públicos de Telecomunicações da Agência Nacional de Telecomunicações (Anatel) e atualmente ocupa o cargo de Assessor Técnico na Subchefia para Assuntos Jurídicos da Casa Civil da Presidência da República. Destacase que as opiniões do autor expressas nesse artigo não representam posicionamentos das instituições mencionadas. Email: victorolfernandes@gmail.com.

FERNANDES, V. O. Regulação dos setores em rede para além dos valores econômicos: uma análise das politicas de interconexão IP para suporte a serviços de voz na União Europeia a partir das Teorias do Interesse Público. Revista de Direito, Estado e Telecomunicações, Brasilia, v. 9, n. 1, p. 143-166, maio de 2017.
} 


\section{Abstract}

Purpose - The study aims to analyze the extent to which economic theories of network industries could anticipate the behavior of regulators regarding the promotion of network access and interconnection policies in telecommunication markets.

Methodology/approach/design - The paper first analyzes the main economic arguments for regulating network industries, in order to highlight the regulatory metalinguistics they contain. Then, the study indicates some critiques to economic rationality addressed by Public Interest Theories of Regulation. At last, it verifies how well economic theories of network industries explain IP interconnection policies recently developed in two European countries, namely, France and Germany.

Findings - European regulator's decisions of imposing IP interconnection obligations on fixed network operators suggest that regulatory intervention on such fields is strongly influenced by non-economic values, such as effective competition and technological neutrality.

Keywords: Regulation, IP interconnection, Public Interest Theories of Regulation.

\section{Introdução}

As principais teorias de regulação dos setores em rede, desenvolvidas a partir de trabalhos clássicos como os de KATZ e SHAPIRO (1994 e 1996) e ECONOMIDES (1996), identificam como características distintivas desses segmentos a existência de condições propícias à formação de monopólios naturais e a tendência de proliferação de efeitos positivos de rede cujos custos podem não vir a ser adequadamente internalizados por produtores e consumidores. Especificamente no âmbito do setor de telecomunicações, estudos recentes que também analisam a necessidade de correção dessas falhas de mercado consideram que, no contexto atual, o dinamismo tecnológico relacionado à busca por inovação seria capaz de, por si só, assegurar níveis elevados de concorrência intra e intersistêmica. Assim, a simples preservação da liberdade negocial seria suficiente para dissipar as externalidades negativas nos mercados, sendo desnecessária uma intervenção estatal mais efetiva na imposição de políticas de acesso e interconexão de redes. (SPULBER; YOO, 2009)

Essas prescrições de liberalização do setor, todavia, contrastam com decisões recentes de Agências Reguladoras Nacionais europeias que têm imposto a operadores de redes fixas e móveis, incumbentes ou não, a obrigação de oferecer interconexão Internet-Protocol (IP) a prestadores de serviços de voz, em condições transparentes e não discriminatórias, a fim de garantir interoperabilidade na transição para o regime de Redes de Próxima Geração (Next Generation Networks - NGN). Tais decisões se baseiam em um quadro normativo comum formado por Diretrizes do Parlamento Europeu e do Conselho da União 
Europeia que consagram como princípios orientadores da atuação das entidades reguladoras nacionais a promoção da concorrência efetiva e a preservação da neutralidade tecnológica das redes.

Considerando esse cenário, o presente artigo objetiva questionar em que medida os postulados econômicos fundantes das teorias de regulação dos setores em rede podem, por si só, antecipar o comportamento de autoridades reguladoras no setor de telecomunicações contemporâneo. A hipótese a ser defendida é a de que, especificamente no contexto examinado, as proposições regulatórias que atribuem o fundamento de legitimidade da intervenção estatal exclusivamente na necessidade de correção de falhas de mercado não seriam capazes de explicar adequadamente a imposição de obrigações de interconexão Internet-Protocol (IP) nas jurisdições europeias. Isso porque a atuação da Agência Reguladoras Nacionais nesses países é informada por um conjunto de princípios normativos que não se reduzem à simples perseguição do ideal econômico neoclássico de eficiência alocativa. A demonstração dessa hipótese será feita tendo como referencial teórico as Teorias de Interesse Público da Regulação, especificamente as abordagens delineadas nas obras de FEINTUCK (2010) e PROSSER (1999), as quais postulam, em síntese, que a racionalidade mercadológica é demasiadamente restrita para contemplar os valores políticos e sociais que orientam a atuação do Estado Regulador nas democracias contemporâneas.

Para atingir o objetivo proposto, o presente trabalho será dividido em 3 (três) seções, além da sua introdução e conclusão. Na primeira seção, serão examinados os principais argumentos que compõem as teorias de regulação econômica de setores em rede, destacando a metalinguagem regulatória que lhes é afeta. Na segunda seção, serão expostas as críticas feitas pelas Teorias do Interesse Público às abordagens regulatórias baseadas exclusivamente na perseguição de valores econômicos. Na terceira seção, serão feitas breves considerações sobre o quadro normativo comum europeu aplicável às políticas de acesso e interconexões de redes e, em seguida, serão analisadas decisões recentes relacionadas a políticas de interconexão IP de duas influentes Agências Reguladoras Nacionais europeias, a Autorité de Régulation des Communications Électroniques et des Postes (França) e a Bundesnetzagentur (Alemanha). ${ }^{1}$ Nosso objetivo será investigar como as abordagens teóricas exploradas nas seções anteriores podem explicar a atuação dessas entidades. Por fim, será feita uma breve conclusão, com o objetivo demonstrar a hipótese de pesquisa delineada.

${ }^{1}$ Conforme será exposto na Seção III do presente artigo, a análise das decisões dessas duas Agências Reguladoras Nacionais afigura-se pertinente pelo fato de elas consignarem, de forma bastante explícita, a aplicação de princípios jurídicos de natureza não puramente econômica positivados no âmbito do chamado Quadro Regulamentar para as Comunicações Eletrônicas da União Europeia (Regulatory framework for Electronic Communications).

FERNANDES, V. O. Regulação dos setores em rede para além dos valores econômicos: uma análise das polititicas de interconexão IP para suporte a serviços de voz na União Europeia a partir das Teorias do Interesse Público. Revista de Direito, Estado e Telecomunicações, Brasilia, v. 9, n. 1, p. 143-166, maio de 2017. 


\section{I - Setores em Rede: características econômicas e especificidades regulatórias}

Embora a estabilização científica da teoria econômica das redes tenha se dado em período relativamente recente, é possível afirmar que os setores em rede são identificados por um conjunto de características estruturais e econômicas, a seguir descritas, que se inter-relacionam, seja condicionando o comportamento dos agentes envolvidos na prestação de serviços, seja conformando as decisões desses agentes. Do ponto de vista estrutural, esses setores são habitualmente explicados a partir dos conceitos e das terminologias da Teoria dos Grafos (Graph Theory). Idealmente, um grafo consiste em um conjunto de nós (vértices) que são interconectados por arestas (lados). Nessa configuração, os nós representam as empresas ou os produtos e as arestas representam as transações econômicas que se estabelecem nos setores em rede. Em mercados como o de transportes terrestres, as rodovias ou ferrovias podem ser consideradas como arestas enquanto que as estações e os pontos de troca entre vias podem ser considerados nós (GOTTINGER, 2003, p. 5). Já no setor tradicional de telecomunicações, os consumidores finais e as estruturas de comutação podem ser identificados como nós, enquanto que todas as formas de comunicação podem ser representadas pelas respectivas arestas (SPULBER e YOO, 2009, p. 19).

Há inúmeras possibilidades de organização dos setores em rede. Alguns dos exemplos mais comuns foram apresentados por ECONOMIDES (1996) em um dos estudos pioneiros sobre o tema e encontram-se abaixo reproduzidos:

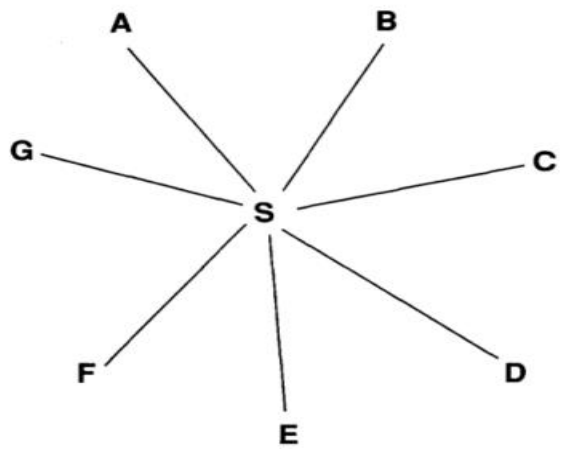

Figura 1 - modelo de setor em rede no formato estrela simples Fonte: (ECONOMIDES, 1996) 


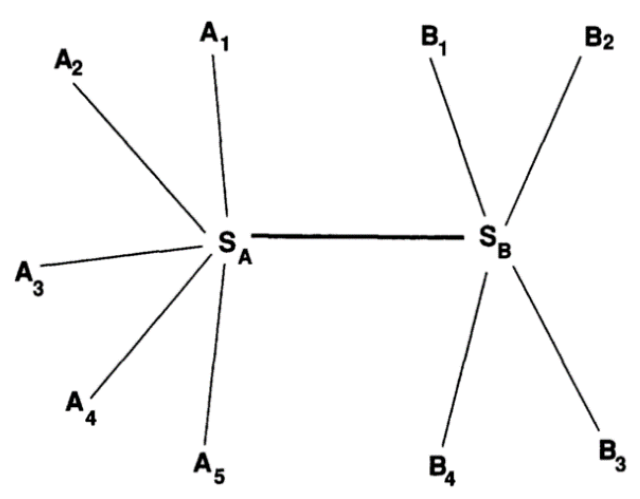

Figura 2 - Modelo de setor em rede no formato estrela dupla (ECONOMIDES, 1996)

Fonte: (ECONOMIDES, 1996)

Os modelos apresentados permitem evidenciar como os produtores e os consumidores finais se relacionam. A Figura 2 acima, por exemplo, pode representar uma rede de telefonia fixa de longa distância (ECONOMIDES, 1996). Os pontos " $\mathrm{S}_{\mathrm{A}}$ " e " $\mathrm{S}_{\mathrm{B}}$ " seriam centrais de comutação que conectariam os consumidores indicados pelos pontos " $\mathrm{A}_{1}$ " a " $\mathrm{A}_{5}$ " aos consumidores representados pelos pontos " $\mathrm{B}_{1}$ " a " $\mathrm{B}_{4}$ ". Uma ligação telefônica do ponto " $\mathrm{A}_{3}$ " a " $\mathrm{B}_{3}$ ", por exemplo, envolveria necessariamente três ligações: uma do consumidor " $\mathrm{A}_{3}$ " para central " $\mathrm{S}_{\mathrm{A}}$ ", uma da central " $\mathrm{S}_{\mathrm{A}}$ " para a central " $\mathrm{S}_{\mathrm{B}}$ " e outra da central " $\mathrm{S}_{\mathrm{B}}$ " para o consumidor " $\mathrm{B}_{3}$ ". Percebe-se que essa mesma estruturação poderia servir para ilustrar malhas ferroviárias ou rodoviárias, onde os pontos " $\mathrm{S}_{\mathrm{A}}$ " $\mathrm{e}$ " $\mathrm{S}_{\mathrm{B}}$ " representariam estações ou pontos de troca e os pontos " $\mathrm{A}_{1}$ " a " $\mathrm{A}_{5}$ " representariam destinos finais.

A partir dessas ilustrações serão explicadas, a seguir, algumas das principais características econômicas dos setores em rede que repercutem sobre a necessidade de adoção de políticas regulatórias e concorrências específicas. É importante ressaltar que referidas características podem ser isoladamente encontradas em outras formações de mercado não abrangidas pela presente análise. Todavia, o traço distintivo dos setores em rede consiste na identificação conjunta e contextualizada de tais elementos.

\section{I.1 - Existência de condições propícias de formação de monopólios naturais e presença de externalidades de rede (network externalitites)}

No âmbito dos setores em rede, é comum se observar a presença de estruturas que se afiguram imprescindíveis para a ligação dos nós que compõem a rede. Na Figura 2, por exemplo, para que os consumidores finais representados 
por " $\mathrm{A}_{1}$ " a " $\mathrm{A}_{5}$ " possam se conectar aos consumidores representados por " $\mathrm{B}_{1}$ " a "B4", não há como se prescindir da ligação " $\mathrm{S}_{\mathrm{A}}-\mathrm{S}_{\mathrm{B}}$ ". Nas hipóteses em que a utilização de composição desse tipo for imprescindível para o acesso ao mercado complementar e a sua duplicação não for economicamente viável, o segmento da rede poderá ser caracterizado como uma infraestrutura essencial (essential facility) ou um engarrafamento monopolista (monopolistic bottleneck), nos termos da tradicional teoria econômica (AREEDA e HOVENKAMP, 1988).

A presença dessas infraestruturas essenciais, associada à existência de significativas economias de escala e de escopo na prestação dos serviços faz com que os setores em redes sejam comumente identificados como monopólios naturais (SHY, 2004, p. 7). O reconhecimento de condições propícias à formação de monopólios naturais no âmbito dos setores em rede, por sua vez, fundamenta a imposição de duas políticas regulatórias tradicionalmente empregadas em setores como os de telecomunicações, energia elétrica e transportes: o controle de tarifas e o controle da entrada de novos agentes no mercado (POSNER, 1969).

Outra característica econômica bastante peculiar dos setores em rede diz respeito à existência dos chamados efeitos de rede (networks effects) e das externalidades de redes (network externalitites). Em um dos clássicos trabalhos sobre o tema, KATZ e SHAPIRO (1985) observam que "a utilidade que um consumidor atribui a certos bens ou serviços varia conforme o número de outros agentes que o consomem" (tradução livre) (p. 424). Pressupondo a existência desse fenômeno, a teoria econômica define que, quando tal utilidade marginal do bem ou serviço cresce em função da procura de outros consumidores, estar-se diante de efeitos externos positivos de rede.

Quando o setor apresenta consideráveis efeitos de rede, por conseguinte, há uma forte tendência de surgimento de uma externalidade negativa específica, chamada de externalidade de rede. Essa externalidade se desenvolve porque o consumidor adicional da rede não é recompensado pelo aumento da utilidade marginal que a sua adesão provoca em relação aos demais usuários (KATZ; SHAPIRO, 1985). A presença dessas externalidades, a seu turno, modifica sensivelmente a análise de eficiência econômica nos setores submetidos a efeitos de rede. Como destaca GOTTINGER (2003, p. 9), enquanto nos mercados tradicionais o resultado do processo competitivo depende principalmente de preços e qualidades dos serviços transacionados, nos ambientes em que os efeitos de rede e as externalidades de rede são significativos, os conflitos entre concorrentes se desenvolvem em outras dimensões, particularmente nas estratégias que as empresas adotam para estabelecer, manter e controlar os padrões (standarts) dentro da indústria.

Em geral, pressupõe-se que as firmas dominantes tenderiam a estabelecer os seus produtos ou serviços como standarts para a prestação do maior número 
possível de serviços adicionais no mercado complementar. Nesse contexto, o agente dominante que primeiro estabelecer seus padrões técnicos no mercado deterá uma importante vantagem competitiva, fechando o sistema à recepção de novas tecnologias (KATZ e SHAPIRO, 1994). Essa situação, chamada pela teoria econômica de "tipping", pode configurar uma falha de mercado com efeitos anticoncorrenciais relevantes, na medida em que, idealmente, os consumidores podem ficar presos à determinada tecnologia vigente no sistema ("locked-in") Como adverte ECONOMIDES (1996), nessas hipóteses, é possível que os consumidores deixem de migrar para uma nova tecnologia, ainda que essa seja mais avançada. Assim, na ausência de medidas regulatórias que efetivamente enderecem tais externalidades de rede, as possibilidades de evolução tecnológica no mercado podem ser limitadas pelas escolhas feitas pelos consumidores no momento em que esses adotaram tal ou qual sistema padronizado ("path dependence").

\section{I.2 - A regulação dos setores em rede no contexto de convergência tecnológica: a relativização dos riscos de fechamento de mercado}

Como ressaltamos, trabalhos recentes têm investigado de que forma as principais características econômicas dos setores em redes analisadas no tópico anterior podem justificar a adoção de políticas regulatórias no setor de telecomunicações contemporâneo. Conforme será destacado nessa seção, estudos como os de SPULBER e YOO (2009 e 2015), tem considerado que, no contexto atual de convergência tecnológica e de crescimento significativo da demanda por serviços de internet, a força propulsora da inovação tenderia a diminuir os riscos de fechamento de mercado provenientes da formação de monopólios naturais e dos efeitos positivos de rede.

O processo de convergência tecnológica consiste numa mudança na forma de prestação de serviços sobre as redes de telecomunicações, ocasionada por uma crescente transmissão de dados digitais através de diferentes plataformas (GARCIA-MURILLO e MACINNES, 2003, p. 57). A principal consequência desse processo é uma ruptura da tradicional relação biunívoca que se estabelecia entre o serviço que é prestado sobre a rede e a tecnologia que lhe dá suporte. ${ }^{2} \mathrm{~A}$ convergência está essencialmente relacionada ao aumento da demanda de consumidores por serviços de dados, à crescente penetração da banda larga para

\footnotetext{
${ }^{2}$ As primeiras leis de liberalização e privatização do setor de telecomunicações foram idealizadas a partir do pressuposto de separação rígida dos serviços de telecomunicações entre si e destes em relação à internet. Esses marcos regulatórios concebiam barreiras regulatórias que tinham que ser transpostas pelos entrantes nos mercados em cada um desses segmentos. Tal arquitetura jurídica amoldava-se ao contexto contemporâneo, já que, do ponto de vista técnico, limitações tecnológicas impediam que uma mesma rede fosse empregada na prestação de mais de um serviço.

FERNANDES, V. O. Regulação dos setores em rede para além dos valores econômicos: uma análise das políticas de interconexão IP para suporte a serviços de voz na União Europeia a partir das Teorias do Interesse Público. Revista de Direito, Estado e Telecomunicações, Brasilia, v. 9, n. 1, p. 143-166, maio de 2017.
} 
além dos grandes centros comerciais e, sobretudo, ao desenvolvimento de novas tecnologias baseadas no uso de protocolos IP que propiciam o surgimento de negócios no meio digital.

Diante dessa mudança de paradigma, o sentido de várias políticas regulatórias historicamente empregadas no setor de telecomunicações é profundamente ressignificado. A pesada regulação das redes de telefonia fixxa, por exemplo, mostra-se anacrônica considerando que grande parte da demanda atual dos usuários se volta a serviços de voz prestados sobre uma rede móvel ou ainda sobre protocolos IP (NUECHTERLEIN e WEISER, 2013, p. 19). Além disso, as políticas de defesa da concorrência ordinariamente desenvolvidas no setor também são desafiadas pelo crescimento significativo da demanda por aplicativos de internet que, em certa medida, afiguram-se substitutivos em relação aos tradicionais serviços de telecomunicações.

É considerando essas transformações econômicas e institucionais provenientes da convergência tecnológica que estudos como os de SPULBER e YOO (2009 e 2015) consideram que dois dos fundamentos tradicionais de regulação dos setores em rede - a teoria dos monopólios naturais e a teoria dos efeitos de rede - não mais seriam capazes de legitimar a intervenção regulatória no setor de telecomunicações contemporâneo. Em primeiro lugar, os autores argumentam que o modelo de monopólio natural somente se configura quando a prestação dos serviços envolve custos excessivamente elevados e capazes de gerar economias de escala que não se exaurem no ciclo ordinário de produção. No entanto, a tendência de esses custos fixos se caracterizarem como típicos custos afundados (sunk costs) passa a ser significativamente mitigada no setor pelo crescimento da demanda por serviços prestados em diferentes redes fixas ou móveis. Em segundo lugar, a aplicabilidade da teoria dos efeitos de redes também passa a ser questionada. Em especial, critica-se a noção de que esses efeitos necessariamente conduziriam a uma situação de fechamento tecnológico (“technological lock-in"). Ao contrário, defende-se que, mesmo quando os efeitos de redes se fazem presentes, as externalidades negativas deles provenientes podem ser dissipadas pelas preferências heterogêneas dos consumidores e, sobretudo, pelos incentivos à adoção de novas tecnologias sistêmicas no contexto de uma concorrência dinâmica.

O principal argumento contraposto ao determinismo da teoria das externalidades de redes se relaciona à necessidade de se pensar as políticas regulatórias a partir da perspectiva de concorrência pelo mercado, ao invés do paradigma de concorrência no mercado. Nesse sentido, SPULBER e YOO (2009, p. 148) sustentam que as externalidades de redes comumente identificadas nos setores em rede poderiam ser compensadas caso a propriedade da rede fosse atribuída a um único detentor que, na sua relação direta com o consumidor, 
poderia internalizar os benefícios da adesão marginal dos usuários. Essa atribuição da propriedade da rede a um único operador, por sua vez, não necessariamente ensejaria uma situação de monopólio. Principalmente nos casos em que houvesse um significativo crescimento do mercado, haveria incentivos para que uma nova tecnologia surgisse, instaurando-se então uma relação de concorrência entre múltiplas redes (p.139).

Ainda segundo os autores, a situação de concorrência em perspectiva dinâmica mostra-se especialmente plausível no setor de telecomunicações contemporâneo, tendo em vista as intensas transformações tecnológicas a que ele tem sido submetido. Nesse contexto, a imposição de barreiras regulatórias à entrada - tipicamente empregada no âmbito de monopólios naturais - traria claros prejuízos ao bem estar dos consumidores. Do mesmo modo, também não mais se justificariam a adoção de políticas de compartilhamento de infraestrutura, como as tradicionais regras de interconexão empregadas no mercado de telefonia fixa. Em relação a essas medidas, os autores argumentam que a obrigatoriedade de interconexão esvaziaria os incentivos ao desenvolvimento de novas tecnologias que aumentariam a capacidade da rede (SPULBER e YOO, 2009, p. 149) (grifos nossos):

"In addition, denying providers of complementary services guaranteed access to the existing network gives them powerful incentives to enter into strategic partnerships with firms interested in constructing alternative network capacity in competition with the existing network. [...] As a result, compelled access can have the perverse effect of entrenching any supposed bottleneck facility by forestalling the emergence of the substitute network technologies. This is particularly problematic in technologically dynamic industries, in which the prospects of developing new ways either to circumvent or to compete directly with the alleged bottleneck are greatest".

Todos esses argumentos embasam a defesa de uma prescrição normativa de regulação do setor de telecomunicações que rejeita quase que em absoluto a possibilidade de intervenção estatal para fins de imposição de obrigações de acesso e interconexão no setor de telecomunicações contemporâneo.

\section{II - Regulação para além de valores meramente econômicos: reflexões a partir das Teorias do Interesse Público}

Na presente seção, nosso objetivo será demonstrar que as abordagens teóricas descritas na seção anterior - mesmo que possam conduzir a respostas divergentes quanto à necessidade ou não de intervenção estatal a partir do reconhecimento de falhas de mercado - são típicas de uma metalinguagem que busca na perseguição de objetivos microeconômicos neoclássicos o fundamento 
universalmente válido de legitimação do Estado regulador. Essa perspectiva, no entanto, negligencia a existência de valores metaeconômicos capazes de orientar a atuação dos agentes reguladores no contexto das democráticas constitucionais contemporâneas, conforme demonstrado pelas Teorias do Interesse Público da Regulação.

As primeiras teorias substantivas de regulação que adquiram notoriedade no contexto político norte-americano na primeira metade do Século XX justificavam a intervenção do Estado no âmbito econômico a partir da tese de que a atuação estatal serviria para corrigir imperfeições naturais dos mercados. Como destaca POSNER (2004), essas teorias tradicionais se baseavam em duas premissas fundamentais: a de que a correção de falhas de mercado levaria ao atingimento de um bem comum econômico e a de que a intervenção regulatória seria "virtualmente gratuita", isto é, imune aos seus próprios.

Embora a referência à necessidade de correção de falhas de mercado seja recorrente em abordagens regulatórias de diversas vertentes, ${ }^{3}$ é possível generalizar que essas proposições se alicerçam na crença de que as autoridades reguladoras devem, ao máximo possível, aproximar as condições de mercados à situação ideal de eficiência de Pareto (STIGLITZ, 2009, p. 6). Assim, em última análise, a intervenção estatal serviria para proporcionar a eficiência alocativa, traduzida na noção de bem-estar social, a partir da instrumentalização de políticas públicas que reduzam custos de transação existentes nos mercados. Nesse paradigma, uma vez que o bem estar social é idealizado em termos de utilidades individuais, o Direito seria operacionalizado para atender à composição de interesse eminentemente privados (OGUS, 2004, p. 25).

Em contraposição ao caráter privatista dessas abordagens, autores como FEINTUCK (2010) e PROSSER (1999) sustentam a necessidade de se fundamentar a legitimidade do Estado regulador em um objetivo maior de proteção do interesse público. Na visão do primeiro autor, essa mudança de paradigma seria necessária, uma vez que a racionalidade mercadológica afigurase restrita demais para englobar uma série de valores políticos e sociais estabelecidos nas democracias liberais e que podem ser vistos, em sua essência, como garantias de ordem constitucional (p. 43).

Tais proposições de legitimação do Estado regulador a partir da defesa do interesse públicos, encontram, no entanto, dois grandes obstáculos. O primeiro deles se relaciona às críticas endereçadas pelas chamadas Teorias Econômicas da Regulação, no sentido de que haveria evidências suficientes de que o bom

\footnotetext{
${ }^{3}$ Acerca das diversas proposições teóricas que invocam a correção de falhas de mercado como fundamento da atuação regulatória, cf. BALDWIN et. al. (2012, p. 15-16).
} 
funcionamento dos setores econômicos seria constantemente comprometido por falhas de governo resultantes da atuação de grupos de interesse que influenciam a elaboração legislativa ${ }^{4}$. Assim, a incapacidade do Estado regulador em atingir objetivos socialmente desejáveis, portanto, estaria relacionado não apenas à sua má-administração, mas principalmente a um jogo de oferta e demanda por regulação no qual os interesses privados constantemente se sobrepõem aos interesses públicos (POSNER, 2004).

Já o segundo obstáculo ao desenvolvimento das Teorias do Interesse Público relaciona-se à falta de precisão semântica do próprio conceito de “interesse público". Essa carência de delimitação terminológica é identificada como um dos principais focos de vulnerabilidade dessas teorias, já que, na omissão de uma definição do conteúdo de interesse público, não haveria parâmetro adequado para se avaliar o êxito de uma intervenção regulatória (FEINTUCK, 2010, p. 43).

Segundo os defensores das Teorias do Interesse Público, a superação dessas críticas exige uma exige uma mudança de perspectiva na compreensão dos fundamentos que legitimam o Estado regulador. Em primeiro lugar, a existência de políticas regulatórias consideradas "mal sucedidas" não necessariamente demonstra que uma intervenção estatal baseada exclusivamente na perseguição de valores econômicos seria capaz de proporcionar melhores resultados do ponto de vista social e democrático (SUSTEIN, 1991). Nesse ponto, as críticas feitas pelas Teorias Econômicas da Regulação se mostram frágeis, pois a compreensão de que as decisões feitas com base no ideal de eficiência alocativa seriam "técnicas" enquanto que as deliberações em matéria de justiça social seriam "políticas" esconde uma falácia de suposta neutralidade e isenção da política econômica (PROSSER, 1999).

Já no que tange à suposta indeterminação do conceito de interesse público, FEINTUCK (2010) defende que a legitimidade da regulação orientada à proteção desse interesse pode ser buscada em valores e princípios assentados na ordem democrática. Nessa perspectiva, considerando de pluralismo da sociedade contemporânea, a definição do interesse público não pode ser feita de forma apriorística; ela deve ser buscada na contínua institucionalização e incorporação desses valores democráticos às práticas regulatórias vigentes.

Tendo em vista essas considerações teóricas, é possível aproximar que as abordagens teóricas sobre setores em rede analisadas na Seção I do presente artigo baseiam-se no pressuposto de que a imposição de medidas regulatórias nesses

\footnotetext{
${ }^{4}$ Embora se reconheça peculiaridades em cada uma das abordagens tratadas, é possível afirmar que os autores vinculados à Teoria da Regulação Econômica em geral se baseiam na clássica afirmação de STIGLER (1971, p. 3) de que "em regra, a regulação é adquirida pela indústria, além da concebida e operada fundamentalmente em seu benefício".
} 
setores se justifica estritamente diante da presença de falhas de mercado, sejam elas associadas à formação de monopólios naturais ou à presença de efeitos externos positivos de rede que induzem externalidades negativas de rede.

Essa metalinguagem regulatória, todavia, desconsidera importantes valores constitucionais que orientam a atuação do Estado regulador no contexto das democracias contemporâneas. Nesse sentido, conforme será analisado na próxima seção, alguns valores de regulação não necessariamente albergados sob o ideal de eficiência alocativa - como os princípios da concorrência efetiva e da neutralidade tecnológica - têm influenciado significativamente a atuação das Agências Reguladoras Nacionais europeias na condução políticas de interconexão IP no âmbito dos estados membros.

\section{III - Análise das regras de interconexão IP na União Europeia: desvendando os fundamentos da intervenção regulatória}

Na presente seção, serão examinadas políticas de interconexão IP que vêm se desenvolvendo na União Europeia nos últimos anos. Nosso objetivo será identificar em que medida as proposições examinadas nos tópicos anteriores podem de fato antecipar resultados sobre a atuação das entidades reguladoras no contexto investigado.

Em diversas jurisdições, o sistema de telefonia fixa se desenvolveu tendo como base a vigência de normas que obrigavam os detentores de redes consideradas de interesse público ("common carrires") a se interconectarem com outros operadores que dela dependiam para prestar seus serviços. A imposição dessas obrigações de interconexão, por sua vez, passou a exigir das autoridades reguladoras o estabelecimento de mecanismos de compensação financeira para que um operador de rede fosse devidamente ressarcido pelos custos adicionais em que incorria ao interconectar usuários de outra rede. No contexto norte-americano, por exemplo, essas políticas de "intercarrier compensation" passaram por sucessivas reestruturações e intensas disputas políticas (NUECHTERLEIN e WEISER, 2013, p. 245).

Com o crescimento da demanda por serviços prestados a partir da internet, iniciou-se um processo de migração das redes de telefonia baseadas na tecnologia de circuito comutado (circuit-switched network), ou de Time Division Multiples (TDM), para um regime de redes baseado na tecnologia de comutação de pacotes (packet-switched network), com grande capacidade de tráfego. A perspectiva é de que, nos próximos anos, essa migração ocorra voluntariamente, de sorte que os serviços de voz sejam inteiramente trafegados na forma de dados a partir de 
protocolos IP no âmbito das chamadas Redes de Próxima Geração (Next Generation Networks $-N G N){ }^{5}$

Nesse contexto de transição, a adequada prestação de serviços de voz depende do estabelecimento de interconexões que possibilitem a troca de dados entre as redes baseadas na tecnologia de TDM e as redes de tecnologia IP. Em especial, essa necessidade de interconexão é acentuada pelo crescimento da demanda por serviços de voz prestados a partir de protocolos IP, os chamados Voice-Over-IP Services (VoIP). Para que usuários desses serviços possam se conectar a usuários de redes de telefonia fixa ou móvel, por exemplo, é necessário que a empresa prestadora do serviço VoIP estabeleça contratos de interconexão com as operadoras daquelas redes. A fim de que a interconexão seja bem sucedida, os dados inicialmente trafegados sobre a rede IP na internet precisam ser convertidos para um formato compatível com a rede de circuito comutado. Somente então a comunicação poderá ser estabelecida com o usuário final de telefonia fixa.

A figura abaixo exemplifica como é prestado o serviço de voz a partir de aplicativos VoIP até um usuário da rede de telefonia fixa comutada tradicional:

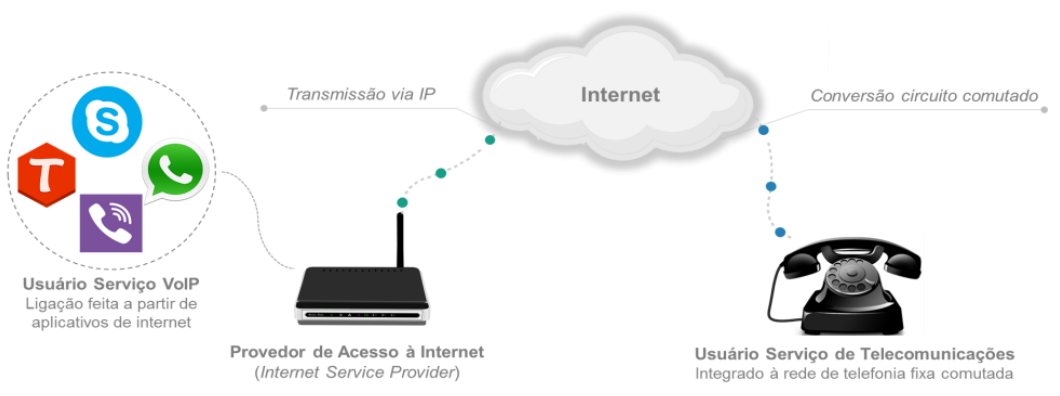

Figura 3 - Exemplo de ligação VoIP feita a partir de uma rede IP a um usuário do serviço de telefonia fixa comutada

Fonte: elaboração própria

Nessa configuração, considerando que os serviços VoIP por vezes se apresentam como substitutivos em relação aos tradicionais serviços de telecomunicações, é factível que os operadores das redes fixas e móveis tenham

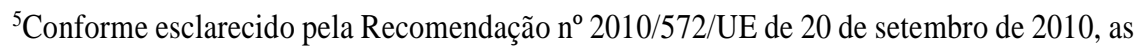
redes de próxima geração (NGA) podem ser entendidas como "redes de acesso cabeadas que são constituídas na totalidade ou em parte por elementos de fibra óptica, e que são capazes de fornecer serviços de acesso de banda larga com características mais avançadas (como maior capacidade de transmissão) em relação às dos fornecidos pelas redes de cobre já existentes. Na maior parte dos casos, as redes NGA resultam de melhorias introduzidas numa rede de acesso de cobre ou coaxial já existente". 
incentivos para recusar a interconexão das suas redes. ${ }^{6}$ Ademais, mesmo quando essa interconexão é oferecida a tradicionais serviços de voz, é possível que a ausência de especificações técnicas ou a divergência de interesses comerciais comprometa a pactuação dos acordos de interconexão.

É com o intuito de dissipar os riscos de recusa à interconexão que Agências Reguladoras Nacionais dos países membros da União Europeia têm proferido decisões administrativas obrigando operadores de redes fixas e móveis a firmar esses acordos em condições não discriminatórias. Antes de analisarmos a atuação dessas autoridades reguladoras, é cabível uma breve exposição acerca do arcabouço normativo europeu comum que orienta a atuação dessas entidades.

\section{III.1 - Contexto normativo comum europeu relativo às políticas de acesso e de interconexão de redes}

No âmbito da União Europeia, a regulamentação dos serviços de telecomunicações é feita pelas Autoridades Reguladoras Nacionais com fundamento na legislação interna dos países membros e também a partir de diretrizes gerais estabelecidas pelo Parlamento Europeu em conjunto com o Conselho da União Europeia. A edição dessas normas de caráter supranacional insere-se no âmbito da política de harmonização da regulamentação dos serviços de comunicações eletrônicas, definida pela Diretiva n ${ }^{\circ}$ 2002/21/CE do Parlamento Europeu e do Conselho da Comissão da União Europeia, de 7 de março de 2002.

Especificamente em relação às políticas de acesso e interconexão, duas diretivas aprovadas pelo Parlamento Europeu e pelo Conselho atribuem às Agências Reguladoras Nacionais competência ampla para a imposição de medidas regulatórias destinadas a garantir a interoperabilidade das redes. Nesse sentido, a Diretiva $n^{\circ}$ 2002/19/CE de 7 de março de 2002, com a redação dada pela Diretiva $n^{\circ}$ 2009/140/EC, de 25 de novembro de 2009, define, em seus artigos $4^{\circ}$ e $5^{\circ}$, que (grifos nossos):

Artigo 4

Direitos e obrigações das empresas

Os operadores das redes de comunicações públicas têm o direito e, quando solicitados por outras empresas autorizadas para 0 efeito, a obrigação, de negociar a interligação entre si com vista à prestação dos serviços de comunicações electrónicas acessíveis

\footnotetext{
${ }^{6} \mathrm{Na}$ Europa, por exemplo, estudo apresentado em 2012 pela Body of European Regulators of Electronic Communications (BEREC) e pela Comissão Europeia chegou a revelar que mais de $50 \%$ (cinquenta por cento) dos operadores de redes móveis atuantes no continente praticavam ou já teriam praticado algum tipo de degradação do tráfego de dados de empresas que oferecem serviços de voz sobre IP. (BEREC - BODY OF EUROPEAN REGULATORS FOR ELETRONIC COMMUNICATIONS, 2012)

FERNANDES, V. O. Regulação dos setores em rede para além dos valores econômicos: uma análise das politicas de interconexão IP para suporte a serviços de voz na União Europeia a partir das Teorias do Interesse Público. Revista de Direito, Estado e Telecomunicações, Brasilia, v. 9, n. 1, p. 143-166, maio de 2017.
} 
ao público, de modo a garantir a oferta e interoperabilidade de serviços em toda a Comunidade. Os operadores oferecerão o acesso e a interligação a outras empresas nos termos e nas condições compatíveis com as obrigações impostas pela autoridade reguladora nacional nos termos dos artigos 5., 6 , 7 e 8

\section{Artigo 5}

Poderes e responsabilidades das autoridades reguladoras nacionais relativamente ao acesso e à interligação

As autoridades reguladoras nacionais devem, agindo em conformidade com os objectivos estabelecidos no artigo 8 da Directiva 2002/21/CE (directiva-quadro), incentivar e, sempre que oportuno, garantir, em conformidade com as disposições da presente directiva, 0 acesso e a interligação adequados, bem como a interoperabilidade de serviços, exercendo a sua responsabilidade de modo a promover a eficiência e a concorrência sustentável e a proporcionar 0 máximo benefício aos utilizadores finais.

Em especial, e sem prejuízo das medidas que possam ser tomadas em relação às empresas que detenham poder de mercado significativo nos termos do artigo 8, as autoridades reguladoras nacionais devem ter a possibilidade de:

a) Na medida do necessário para garantir a ligação de extremoa-extremo, impor obrigações às empresas que controlam 0 acesso aos utilizadores finais, incluindo, em casos justificados, a obrigação de interligarem as suas redes quando ainda não estiverem interligadas;

b) $\mathrm{Na}$ medida do necessário para garantir a acessibilidade dos utilizadores finais aos serviços de radiodifusão digital de rádio e televisão especificados pelo Estado-Membro, impor aos operadores a obrigação de oferecerem acesso aos outros recursos mencionados no anexo I, parte II, em condições justas, razoáveis e não discriminatórias.

2. Ao imporem a um operador obrigações de oferta de acesso em conformidade com 0 artigo 12, as autoridades reguladoras nacionais podem fixar condições técnicas ou operacionais, a serem cumpridas pelo fornecedor e/ou beneficiários de tal acesso, de acordo com o direito comunitário, quando necessário para garantir o funcionamento normal da rede. As condições que incidam na aplicação de normas ou especificações técnicas específicas deverão obedecer ao disposto no artigo 17.0 da Directiva 2002/21/CE (directiva-quadro).

3. As obrigações e as condições impostas nos termos dos nos $1 \mathrm{e}$ 2 deverão ser objectivas, transparentes, proporcionadas e não discriminatórias, e ser aplicadas em conformidade com 0 
procedimento previsto nos artigos 6.0 e 7.0 da Directiva 2002/21/CE (directiva-quadro).

Conforme referido pelo artigo $5^{\circ}$ acima destacado, a adoção de políticas de interconexão de rede por parte das Agências Reguladoras Nacionais se fundamenta principiologicamente no conteúdo do artigo $8^{\circ}$ da Diretiva $n^{\circ}$ 2002/21/CE de 7 de março de 2002, que estabelece o princípio da neutralidade tecnológica enquanto objetivo que deve orientar a intervenção regulatória, principalmente quando a finalidade for promover a concorrência efetiva nos mercados:

\section{Artigo 8}

Objectivos de política geral e princípios de regulação

1. (...) Os Estados-Membros deverão assegurar que as autoridades reguladoras nacionais, no desempenho das funções de regulação constantes da presente directiva e das directivas específicas, e nomeadamente das destinadas a assegurar uma concorrência efectiva, tomem na máxima conta que é desejável garantir a neutralidade tecnológica da regulamentação.

Além das referidas diretivas, em 20 de setembro de 2010, a Comissão Europeia aprovou a Recomendação $n^{\circ}$ 2010/572/UE, que estabelece orientações específicas sobre o acesso regulamentado às redes de próxima geração (Next Generation Networks). Nesse ato, considerou-se que as Agências Reguladoras Nacionais deveriam examinar atentamente as novas condições de concorrência resultantes da implantação de redes NGA e avaliar, no âmbito do procedimento de análise de mercados relevantes, a necessidade de imposição de medidas específicas de compartilhamento de redes aos agentes econômicos detentores de Poder de Mercado Significativo (PMS), bem como aos agentes que controlam infraestruturas cuja duplicação não seja econômica ineficiente ou fisicamente impraticável.

Segundo a Recomendação, nas hipóteses em que fosse constatada a existência de PMS ou condição análoga, as Agências Reguladoras Nacionais deveriam garantir o acesso à chamada "infraestrutura física da rede" a terceiros, com base em preços orientados para os custos e respeitando o princípio da equidade. Quando à fixação de preços, o Anexo I da Recomendação estabelece que as Agências Reguladoras Nacionais devem avaliar se a duplicação das infraestruturas de acesso às redes NGN é economicamente viável e eficiente. Caso não o seja, as entidades reguladoras devem atuar para "criar condições de concorrência verdadeiramente equitativas entre a componente a jusante do FERNANDES, V. O. Regulação dos setores em rede para além dos valores econômicos: uma análise das políticas de interconexão IP para suporte a serviços de voz na União Europeia a partir das Teorias do Interesse Público. Revista de Direito, Estado e Telecomunicações, Brasilia, v. 9, n. 1, p. 143-166, maio de 2017. 
operador com PMS e outros operadores de rede”. Já quanto à aplicação do princípio da equivalência no acesso à infraestrutura de rede, o Anexo II da Recomendação deixa claro que (grifos nossos):

ANEXO II da Recomendação n ${ }^{\circ}$ 2010/572/UE, de 20 de setembro de 2010

Aplicação do princípio da equivalência no acesso à infraestrutura de engenharia civil do operador com poder de mercado significativo (PMS) para efeitos de instalação de redes NGA

As ARN devem exigir que o operador com PMS forneça acesso à sua infra-estrutura de engenharia civil nas mesmas condições a internos a terceiros interessados. Em particular, o operador com PMS deve divulgar todas as informações necessárias sobre as características da infra-estrutura e aplicar os mesmos procedimentos para o pedido e para o fornecimento de acesso. As ofertas de referência e os acordos sobre o nível de serviço são fundamentais para garantir a correcta aplicação do princípio da equivalência.

Vê-se, portanto, que o quadro normativo comum europeu e a Recomendação $n^{\circ}$ 2010/572/UE, de 20 de setembro de 2010 acentuam expressamente o poder/dever das Agências Reguladoras Nacionais de impor obrigações de interconexão de redes no contexto de transição de redes de próximas geração, tendo como base princípios como o da concorrência efetiva e o da neutralidade tecnológica.

É considerando esse pano de fundo normativo que serão analisadas decisões de duas das mais influentes Agências Reguladoras Nacionais europeias, a fim de se verificar em que medida se pode dizer que esses valores de natureza não puramente econômica de fato orientaram a atuação dessas entidades nos contextos analisados.

\section{III.2 -Políticas de interconexão IP para suporte a serviços de voz no contexto da União Europeia (UE): uma análise de decisões recentes de duas Agências Reguladoras Nacionais}

Até o início da década de 2000, os acordos de interconexão IP firmados no âmbito da União Europeia não se sujeitavam a interferências consideráveis por parte dos Estados membros (MARCUS, 2008). Como mostra o resultado de Consulta Pública feita pelo Grupo de Reguladores Europeus (European Regulators' Group), nos anos de 2007 e 2008, embora os problemas da migração para redes NGN já fossem considerados pelas autoridades, somente um pequeno número de Agências Reguladoras Nacionais reconhecia as políticas de interconexão IP como prioritárias (EUROPEAN REGULATORS GROUP, 2007) FERNANDES, V. O. Regulação dos setores em rede para além dos valores econômicos: uma análise das politicas de interconexão IP para suporte a serviços de voz. na União Europeia a partir das Teorias do Interesse Público. Revista 
Esse cenário se alterou significativamente nos últimos anos. Em 2015, a Body of European Regulators for Eletronic Communications (BEREC) apresentou o report intitulado "Case Studies on IP-based Interconnection for Voice Services in the European Union", no qual se avaliou o estágio atual de migração para redes all-IP no âmbito dos países membros da União Europeia. A publicação apontou que, até o final daquele ano, Agências Reguladoras Nacionais de 9 (nove) países já haviam imposto aos operadores de redes fixas, incumbentes ou não incumbentes, e de redes móveis obrigação de fornecer interconexão IP de suas redes para tráfego de dados de serviços de voz. Em 3 (três) desses países, as autoridades impuseram essa obrigação aos operadores de redes fixas incumbentes também para a originação de chamadas (BEREC - BODY OF EUROPEAN REGULATORS FOR ELETRONIC COMMUNICATIONS, 2015).

Com o intuito de explorar os contornos dessas políticas de interconexão IP, nas próximas subseções serão feitas breves descrições sobre os resultados apresentados pelo estudo da BEREC (2015) em relação a dois países específicos, França e Alemanha. O objetivo da nossa análise será desvendar em que medida valores não econômicos cristalizados nas diretivas da União Europeia em matéria de interconexão e acesso de rede - como o princípio da concorrência efetiva e da neutralidade tecnológica - foram determinantes para a construção das decisões das Agências Reguladoras Nacionais.

\section{III.2.a - França}

Na Franca, a obrigatoriedade de oferta de interconexões IP foi primeiramente firmada pela Autorité de Régulation des Communications Électroniques et des Postes (ARCEP) na Décision n ${ }^{\circ}$ 2011-0926, de 26 de julho de 2011. A decisão foi tomada no âmbito do processo de revisão dos mercados relevantes de telefonia fixa, no qual se considerou que a empresa incumbente France Télécom dispunha de PMS em todos os mercados relevantes de telefonia de varejo e atacado. A Agência Reguladora considerou que, no contexto de transição para um regime de redes NGN, seria necessário que a France Télécom analisasse com razoabilidade os pedidos de acesso e readequação da sua arquitetura de interconexão feitos por terceiros, de modo a não distorcer o jogo competitivo (jue concurrentiel). (FRANÇA, 2011, p. 68)

A ARCEP considerou que o grande tamanho da rede da France Télécom poderia gerar externalidades negativas significativas no mercado e ressaltou que as decisões da empresa quanto ao número e à localização dos seus pontos de interconexão poderiam gerar consequências significativas nos negócios de outras operadoras de redes fixas e móveis. A agência examinou ainda manifestações de operadoras como a Bouygues Telecom, a Colt e a Verizon, que se queixaram da 
arquitetura de interconexões da France Télécom, principalmente em relação às interconexões IP, relatando dificuldades no acesso à rede da incumbente. (p. 70).

Considerando esses fatos, a Autoridade Reguladora entendeu, especificamente em relação às interconexões IP, que a France Télécom deveria realizar, naquilo que fosse possível, adaptações na sua infraestrutura de rede, a fim de oferecer uma interconexão eficiente para transporte de dados em ligações de voz, independente da natureza geográfica ou não do número chamado. Com o intuito de evitar a descontinuidade imediata das interconexões TDM, a AERCEP também definiu que a France Télécom deveria continuar a ofertar interconexões baseadas na tecnologia TDM por pelo menos 18 (dezoito) meses, a contar de dezembro de 2014.

Nos termos do art. 13 da parte dispositiva da decisão, estabeleceu-se que a France Télécom seria obrigada a conceder os pedidos razoáveis de terceiros de acesso para elementos de rede, ou a meios associados. Nesse ponto, o próprio comando normativo expressa que essa medida tem por finalidade assegurar uma concorrência leal e efetiva (concurrence effective et loyale) (grifos nossos):

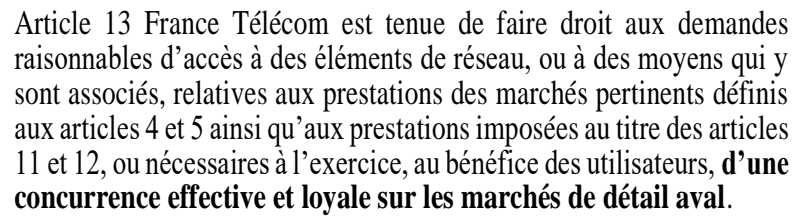

O dispositivo também estabelece que a incumbente deveria, dentre outros: (i) negociar de boa-fé com os operadores que requerem acesso; (ii) abster-se de retirar o acesso de operador a que já se tenha concedido, a menos que seja feito acordo prévio entre a Autoridade Reguladora e o operador; (iii) conceder acesso aberto a interfaces técnicas, protocolos ou outras tecnologias que são indispensáveis para a interoperabilidade dos serviços ou serviços de rede virtual; (iv) prestar serviços específicos necessários para garantir interoperabilidade dos serviços de ponta a ponta, em particular no que respeita à significa referentes aos serviços de rede inteligentes e (v) fornecer acesso a sistemas de apoio operacional ou a sistemas de software.

Desse modo, é possível afirmar que a decisão da Autoridade Reguladora francesa demonstra uma preocupação com os riscos de fechamento de mercado e com os riscos de comprometimento da interoperabilidade de redes no contexto de transição para o regime de redes NGN. 


\section{II.2.b - Alemanha}

Na Alemanha, em agosto de 2013, a Bundesnetzagentur, no âmbito do procedimento de análise dos mercados relevantes de chamadas de voz em redes móveis individuais, determinou que a incumbente de telefonia fixa Deutsche Telekom $A G$ estaria obrigada a fornecer interconexão IP a outros operadores de redes fixas e móveis (Decisão BK3d-12/009, da Beschlusskammer 3, de 30 de agosto de 2013). (ALEMANHA, 2013).

A avaliação feita pela Agência Reguladora concluiu que a Deutsche Telekom $A G$ e suas subsidiarias continuavam a apresentar PMS nos mercados nacionais de originação de chamadas na rede telefônica fixa publica. A questão controvertida era se esse PMS, que já fundamentava a imposição de obrigações de interconexão PSTN, também poderia servir justificar a imposição de obrigações de interconexão IP. (p. 6)

A Agência Reguladora destacou que, em 2011, a Deutsche Telekom AG começou a realizar interconexões IP, com o intuito de transformar suas redes em redes de próxima geração (NGN). Por meio de uma comunicação formal encaminhada à empresa, a Bundesnetzagentur já havia informado a intenção de estender as obrigações de interconexão PSTN para a interconexão IP. A incumbente de telefonia fixa, no entanto, rejeitava essa possibilidade, argumentando que o processo de transição para redes NGN ainda se encontrava nos seus estágios iniciais e que, por isso, não seria possível cumprir eventual obrigação de interconexão IP, senão de forma gradual. Além disso, a Deutsche Telekom AG também destacava o potencial de conflito com outros operadores de rede, relacionado às dificuldades de fixação de referências técnicas para as interconexões. (p. 8).

A Bundesnetzagentur apreciou manifestações de outras operadoras de redes fixas que alegavam a impossibilidade de a Deutsche Telekom AG fornecer conexões IP suficientemente rápidas por falta de capacidade. As empresas sustentavam também que decisões importantes no processo de migração para redes NGN não poderiam ser deixadas ao arbítrio da Deutsche Telekom AG, sob pena de violação do princípio da neutralidade tecnológica, motivo pelo qual deveriam ser predefinidos cenários de migração para os próximos anos. .(p. 9-10). Com base nesses fundamentos, empresas como a 01051 Telecom, a Callax Telecom e a MEGA Communications pleiteavam, dentre outros pedidos, a imposição de parâmetros para a oferta de interconexões IP por parte da Deutsche Telekom $A G$, inclusive com a publicação de referências técnicas de sua rede. (p. 13).

Interpretando que a existência de PMS da Deutsche Telekom AG no segmento de serviços de telefonia fixa também se estendia à provisão de 
interconexões, a agência reguladora entendeu que a obrigação de fornecer acesso à sua rede para fins de trânsito interno a outros operadores deveria não apenas ser mantida nas interconexões PSTN, mas também estendida às interconexões IP. A decisão considerou real o risco de a interoperabilidade e a concorrência efetiva no mercado virem a ser comprometidas por eventuais recusas de interconexão por parte da Deutsche Telekom AG (p. 29). A Bundesnetzagentur deixou claro ainda que a incumbente deveria ofertar interconexões IP não apenas para outras operadoras de redes fixas, mas também para operadoras de redes móveis, tanto nas terminações quanto nas originações de chamadas. Também se reforçou a necessidade de que, durante o processo de transição para redes de próxima geração, fossem mantidas as ofertas de interconexões PSTN em conjunto com as de interconexões IP. (p. 35).

Assim como na decisão da Autoridade Reguladora francesa, a força normativa do preceito da concorrência efetiva se mostrou fundamental para a imposição de obrigações de interconexão IP por parte da Bundesnetzagentur. É a partir desse diagnóstico que será delineada a conclusão do presente artigo.

\section{Conclusão}

Conforme analisado, as teorias de regulação dos setores em rede tradicionalmente racionalizam a possibilidade de intervenção regulatória a partir de uma metalinguagem de correção de falhas de mercado. Estudos recentes têm entendido que, especificamente no âmbito do setor de telecomunicações contemporâneo, o dinamismo tecnológico relacionado à busca por inovação seria capaz de, por si só, assegurar a superação dessas falhas, sendo desnecessária, portanto, a adoção de políticas mais efetivas de acesso e interconexões de redes por parte de agências reguladoras setoriais.

As discussões quanto à necessidade de adoção de políticas desse gênero se tornam ainda mais relevantes na atualidade, tendo em vista, na maioria dos países, o andamento do processo de transição para o regime de redes de próxima geração (redes NGN). Nesse sentido, no âmbito da União Europeia, expediu-se a Recomendação $n^{\circ}$ 2010/572/UE, de 20 de setembro de 2010, que reforça o poder/dever das Agências Reguladoras Nacionais de impor obrigações de interconexão de redes, com base nos valores de concorrência efetiva e de neutralidade tecnológica.

Considerando a necessidade de se investigar de forma mais aprofundada a atuação de Autoridades Reguladoras Nacionais europeias em relação ao tema, foram analisadas decisões recentes da Autorité de Régulation des Communications Électroniques et des Postes (ARCEP) e da Bundesnetzagentur que impuseram aos operadores de redes fixas incumbentes a obrigação de fornecer 
interconexões IP a outros operadoras de redes fixas e móveis. Conforme observamos na seção anterior, tais decisões conferem bastante relevo ao princípio da neutralidade tecnológica e ao princípio da concorrência efetiva, compreendendo-se, em relação a esse último, a necessidade de se preservar o equilíbrio competitivo sob uma perspectiva estática e intrassistêmica nos mercados de acesso à infraestrutura de telefonia fixa, garantindo-se o acesso às redes por parte de terceiros a preços justos e em condições não discriminatórias.

Esses resultados de intervenção regulatória, por sua vez, afiguram-se significativamente distoantes das postulações de autores como SPULBER e YOO (2009), que compreendem que os riscos de fechamento de mercado no setor de telecomunicações seriam naturalmente dissipados no longo prazo. Considerando os apontamentos feitos pelas Agências Reguladoras Nacionais quanto à imprescindibilidade da imposição de obrigações de acesso e interconexão de redes, parece pouco plausível que, nas jurisdições examinadas, a concentração temporária das redes nas mãos de um único agente monopolista possa gerar incentivos à adoção de novas tecnologias sistêmicas num ciclo de concorrência destrutiva.

Essas constatações nos permitem afirmar que as teorias analisadas da Seção I do presente trabalho não seriam capazes de antecipar o comportamento dos agentes reguladores no contexto examinado. Isso porque elas se lastreiam numa metalinguagem regulatória que aponta como fundamento exclusivo da intervenção estatal a perseguição de valores econômicos neoclássicos, como a correção de falhas de mercado e a maximização do bem-estar social e da eficiência alocativa. Tal qual analisado na Seção II deste trabalho, essas abordagens econômicas mostram-se insuficientes para abarcar a pluralidade de valores substantivos que orientam e legitimam a atuação do Estado Regulador no contexto das democracias constitucionais, como os princípios da neutralidade tecnológica e da concorrência efetiva, tão determinantes para a estruturação das políticas de interconexão IP no contexto europeu.

Ainda que de forma precária e com todas as limitações afetas à presente análise, este artigo objetivou demonstrar a hipótese de pesquisa proposta, com o intuito de contribuir para o aprimoramento de uma reflexão crítica acerca dos pressupostos teóricos que legitimam a intervenção regulatória nos setores em rede.

\section{Referências Bibliográficas}

ALEMANHA. Bundesnetzagentur. Beschluss wegen der Beibehaltung, der Auferlegung und des Widerrufs von Verpflichtungen auf den Märkten „Verbindungsaufbau im öffentlichen Telefonnetz" und 
„Anrufzustellung in einzelnen öffentli- chen Telefonnetzen an festen Standorte. p. 1-85, 2013.

BALDWIN, R.; CAVE, M.; LODGE, M. Understanding Regulation. $2^{\mathrm{a}}$ ed. Nova Iorque: Oxford University Press, 2012.

BEREC - BODY OF EUROPEAN REGULATORS FOR ELETRONIC COMMUNICATIONS. A view of traffic management and other practices resulting in restrictions to the open Internet in Europe. p. 1-39, 2012.

BEREC - BODY OF EUROPEAN REGULATORS FOR ELETRONIC COMMUNICATIONS. Case Studies on IP-based Interconnection for Voice Services in the European Union, p. 1-75, 2015.

ECONOMIDES, N. The Economics of Networks. International Journal of Industrial Organization, v. 14, p. 673-699, 1996.

EUROPEAN REGULATORS GROUP. ERG Common Statement on Regulatory Principles of IP-IC/NGN Core - A work program towards a Common Position, 2007.

FEINTUCK, M. Regulatory Rationales Beyond The Economic: In Search of The Public Interest. In: The Oxford Handbook of Regulation. Nova Iorque: Oxford University Press, 2010. p. 39-63.

FRANÇA. Décision n ${ }^{\circ}$ 2011-0926 en date du 26 juillet 2011 - Décision portant sur la définition des marchés pertinents de la téléphonie fixe, la désignation d'opérateurs exerçant une influence significative sur ces marchés et les obligations imposées à ce titre, 2011.

GARCIA-MURILLO, M.; MACINNES, I. The Impact of Technological Convergence on The Regulation of ICT Industries. International Journal on Media Management, v. 5, n. March 2013, p. 57-67, 2003.

GOTTINGER, H.-W. Economies of Network Industries. London and New York: Routledge Taylor and Francis Group, 2003.

KATZ, M. L.; SHAPIRO, C. Network Externalities, Competition, and Compatibility. The American Economic Review, v. 75, n. 3, p. 424-440, 1985.

KATZ, M. L.; SHAPIRO, C. Systems Competition and Network Effects. The Journal of Economic Perspectives, v. 8, n. 2, p. 93-115, 1994.

MARCUS, J. S. IP-based NGNs and interconnection: the debate in Europe. Communications \& Strategies, v. 1, n. 72, p. 17-32, 2008. 
NUECHTERLEIN, J. E.; WEISER, P. J. Digital Crossroads: Telecommunications Law and Policy in The Internet Age. 2. ed. Cambridge, Massachusetts: The MIT Press, 2013.

OGUS, A. Regulation: Legal Form and Economic Theory. Oxford e Portland, Oregon: Hart Publishing, 2004.

POSNER, R. A. Teorias da Regulação Econômica. In: Regulação Econômica e Democracia: o debate norte-americano. São Paulo: Editora 34, 2004. p. 301.

PROSSER, T. Theorising Utility Regulation. The Modern Law Review, v. 62, n. 2, p. 196-217, 1999.

SHY, O. The Economics of Network Industries. Cambridge: Cambridge University Press, 2004.

SPULBER, D. F.; YOO, C. S. Networks in Telecommunications. New York: Cambridge University Press, 2009. 